\title{
On the Compressive Strength Prediction for Concrete Masonry Prisms
}

\author{
Cláudius S. Barbosa ${ }^{1}$; Paulo B. Lourenço ${ }^{2}$ and João B. Hanai ${ }^{3}$
}

\begin{abstract}
The results of a combined experimental program and numerical modeling program to evaluate the behavior of ungrouted hollow concrete blocks prisms under uniaxial compression are addressed. In the numerical program, three distinct approaches have been considered using a continuum model with a smeared approach, namely plane-stress, plane-strain and threedimensional conditions. The response of the numerical simulations is compared with experimental data of masonry prisms using concrete blocks specifically designed for this purpose. The elastic and inelastic parameters were acquired from laboratory tests on concrete and mortar samples that constitute the blocks and the bed joint of the prisms. The results from the numerical simulations are discussed with respect to the ability to reproduce the global response of the experimental tests, and with respect to the failure behavior obtained. Good agreement between experimental and numerical results was found for the peak load and for the failure mode using the three-dimensional model, on four different sets of block/mortar types. Less good agreement was found for plain stress and plain strain models.
\end{abstract}

Keywords: Numerical modeling; Experimental testing; Structural masonry; Hollow concrete blocks prisms; Compression failure.

${ }^{1}$ Ph.D. in Civil Engineering, Department of Structural Engineering, University of Sao Paulo, School of Engineering at Sao Carlos, 13566-590 Sao Carlos, Brazil. E-mail: claudiusbarbosa@yahoo.com.br

${ }^{2}$ Professor, ISISE, Department of Civil Engineering, University of Minho, Azurém, 4800-058 Guimaraes, Portugal. E-mail: pbl@civil.uminho.pt

3 Professor, Department of Structural Engineering, University of Sao Paulo, School of Engineering at Sao Carlos, 13566-590 Sao Carlos, Brazil.E-mail: jbhanai@sc.usp.br 


\section{Introduction}

The last years witnessed significant advances in masonry mechanics, both with respect to experimental testing and to numerical modeling. Despite this fact, the composite behavior of hollow concrete block masonry still represents a true challenge. Hollow concrete blocks are structures constituted by slender walls, interacting between themselves and usually featuring different geometries. Besides the difficulties inherent to characterize the mechanical properties of mortar inside the composite, also the mechanical properties of the concrete from the blocks are usually not known, since the tests are carried out on full blocks.

With respect to the difficulty of characterizing the materials that constitute masonry on laboratory tests, it can be emphasized that tests carried out on masonry units with flat platens provide an artificial compressive strength due the restraint effect of platens, that the post-peak behavior in compression is usually not determined, that the fracture energy in compression $\left(G_{f_{C}}\right)$ depends significantly on the test set-up and equipment, that the load conditions of units and mortar tests do not reproduce the state of stress of the composite inside the masonry and that the mortar specimens cast in steel molds do not represent the real curing conditions (Stöckl et al. 1994).

In order to carry out sophisticated numerical analyses, it is necessary to further advance in the characterization of the properties of materials and assemblage (Marzahn 2003; PinaHenriques and Lourenço 2006). One example of an attempt to provide detailed information on the behavior of hollow block masonry has been made by modeling the prism behavior using a block Young's modulus obtained from tests on samples extracted from concrete blocks (Hamid and Chukwunenye 1984). Similarly, tests have been performed in samples extracted from hollow concrete, calcium silicate and solid concrete blocks to identify the compressive and tensile 
strength, together with the Young's modulus (Hawk et al. 1997; Ganzerli et al. 2003; Marzahn 2003).

Tests on cylindrical samples (50x100 mm) made from concrete with zero slump used in hollow concrete blocks manufacturing, demonstrated that the compressive strength of the samples was lower than the actual block strength, due to the pressure and curing inherent to the production process (Frasson Junior 2000).

Considerable difficulties are therefore expected in any research aiming at characterizing the mechanical properties of masonry components. For this reason, the present paper adopts a different approach to ensure adequate definition of the stress-strain relationship of masonry components. Laboratory tests were carried out on hollow concrete blocks, masonry prisms, and concrete and mortar samples that constitute the masonry elements. The adopted technique was to mold the blocks in the laboratory using a concrete mix also used to cast concrete samples (Barbosa 2004).

Modeling of masonry itself is a complex task due to the heterogeneity and orthotropy caused by masonry components and their interfaces. Mortar joints act usually as planes of weakness and, depending of the level of accuracy and the simplicity, micro-modeling of individual components, block and mortar, or macro-modeling of masonry as a composite can be adopted (Lourenço 1996).

In the case of masonry compression failure, discontinuum models showed clear advantages when compared to continuum models, based in plasticity and cracking, in predicting the compressive strength and peak strain of solid brick prisms from the properties of the constituents (Pina-Henriques and Lourenço 2006; Lourenco and Pina-Henriques 2006). This is 
true for solid masonry, whereas for hollow block masonry the application of such models seems cumbersome due to the geometrical complexity of the masonry basic cell.

Only a few numerical researches have been carried out with respect to the strength prediction of hollow concrete block masonry (e.g., Page and Shrive 1990; SayedAhmed and Shrive 1996; Koksal et al. 2005) and, even if grouted masonry is usually considered, the material properties are not always fully available from testing and it is not always demonstrated that the ultimate load is the true one, and not the result of divergence of the numerical solution procedure. In this research program, the numerical analysis is based on continuum finite elements utilizing a commercial non-linear finite element code DIANA (DIANA 2005).

In total, four different combinations of mortar and block were simulated, utilizing the parameters obtained from the experimental program to validate the constitutive behavior obtained in masonry prisms. It is shown that good agreement can be obtained in the prediction of the behavior of prisms using advanced numerical simulations.

\section{Experimental results}

The experimental research program was carried out in the Laboratory of Structural Engineering at the University of Sao Paulo, Sao Carlos (Brazil). The blocks were molded with concrete mixes with four different strengths. This technique ensures that the mechanical properties from concrete specimens adequately represent the behavior of hollow concrete blocks (Barbosa 2004). Concrete hollow block are manufactured utilizing a zero slump concrete, together with high pressure and vibration of the molds, which is not reproduced here. Still, the adopted procedure allows to ensure identical mechanical properties for the blocks and the samples, thus guaranteeing a comparison of results with a single material. 
Here, the blocks have been cast together with cylindrical specimens of diameter $\mathrm{d}=100 \mathrm{~m}$ and height $\mathrm{h}=200 \mathrm{~mm}$, and rectangular beams with dimensions: wxdxL = 150x150x500mm.

The block geometry is depicted in Fig. 1, where it is shown how two expanded polystyrene elements allow to shape the hollow cores inside the blocks.

Masonry prisms have been built with the molded blocks, with three blocks stacked and $10 \mathrm{~mm}$ bed mortar joint. Cylindrical samples $(50 \times 100 \mathrm{~mm})$ and beams (150x150x500 mm) were again molded with four different mix mortars that constituted the bed joint of prisms. The concrete and mortar elements followed the same manufacturing steps: casting, vibration and curing.

The cylindrical specimens were manufactured according to Brazilian standards. Although there are differences on the samples dimensions, the ratio height/thickness $(h / t=2)$ is kept. On other hand, the beams were molded according to RILEM TC 50-FMC (1985), in order to obtain the fracture mechanics parameters. This recommendation foresees the same sample dimensions for mortar and concrete samples.

Therefore, four sets with distinct concrete and mortar mechanical properties were considered in total. The masonry prisms, together with concrete and masonry specimens, were subjected to axial compression using a servo-hydraulic machine and tested under displacement controlled mode with a constant displacement velocity. The controlled displacement mode allows, in principle, the acquisition of the complete stress-strain diagram, including its descending or softening branch. A displacement rate of $0.005 \mathrm{~mm} / \mathrm{s}$ was adopted on the compressive tests samples, while, on the prism tests, the adopted rate was $0.001 \mathrm{~mm} / \mathrm{s}$. The three-point bending tests were carried out with open notched control of $0.02 \mathrm{~mm} / \mathrm{min}$. 
Additional tests with cylindrical specimens determined the tensile strength of concrete and mortar by means of the diametral compressive test on cylindrical samples and three-point bending tests on notched beams provided the fracture energy parameters for both materials.

The prisms were instrumented on face-shells with horizontal and vertical LVDTs in the center of each hollow core. Additional LVDTs measure the vertical displacement in the block and mortar individually. The prisms and mortar specimens are shown in Fig. 2.

\section{Details on mortar and concrete composition}

The concrete was prepared using Portland cement similar to type III, standardized in ASTM C 150 (2007), due the importance of high-early strength at 14 days-after molding (foreseen date for tests). The coarser aggregates were obtained from basaltic rocks with the following characteristics:

- mass per unit volume (density): $2.71 \mathrm{~g} / \mathrm{cm}^{3}$;

- apparent mass per unit volume: $1.37 \mathrm{~g} / \mathrm{cm}^{3}$;

- fineness modulus: 2.78;

- maximum aggregate size: $9.5 \mathrm{~mm}$

- absorption: $2.3 \%$.

The following characteristics were obtained for sand, the fine aggregate of concrete:

- mass per unit volume (density) is $2.48 \mathrm{~g} / \mathrm{cm}^{3}$;

- apparent mass per unit volume : $1.48 \mathrm{~g} / \mathrm{cm}^{3}$;

- fineness modulus: 2.08;

- maximum aggregate size: $2.4 \mathrm{~mm}$. 
The components for mortar are cement, lime and sand. The properties of cement and sand are similar to the concrete mix ones. The main function of lime is to provide high water retention capacity and plasticity for the mortar.

The four different concrete and mortar mix proportions are presented in Table 1.

\section{Manufacturing of elements and behavior under compressive loading}

The blocks were cast and vibrated from a single batch in a vibrating table. From the same concrete batch, the samples were also molded as depicted in Fig. 3. After 24 hours, the blocks and samples (cylindrical and beams) were demolded and stored at temperature/humidity chamber ate $20^{\circ} \mathrm{C}$ and $95 \%$ relative humidity, for seven days. After curing, the elements were kept under laboratory temperature and humidity.

Top and bottom surfaces of cylindrical samples are ground by a mechanical process and the beams were notched. The next step was to mark the location of instrumentation on the elements to be tested.

The masonry prisms were built with the same mortar batch from which the samples were cast. Vibration of mortar samples was on the same vibration table. The samples were demolded after 24 hours and kept close to the prisms (Fig. 2), under laboratory conditions.

The failure mode observed in concrete and mortar samples during the compressive test is characterized by the typical diagonal shear. On diametral compressive tests the crack arises under load line near the maximum force of the test. Due to the low rate velocity test it is possible to avoid the sudden failure of samples.

The prisms were instrumented with displacement transducers (LVDTs) to obtain the vertical strain. Four strain gages were glued in the cylindrical samples (two in the vertical direction and two in the radial direction) to acquire the Young's modulus and Poisson's ratio of 
concrete and mortar. In the beams, the vertical displacement was obtained by means of a displacement transducer.

A loading steel plate with $35 \times 200 \times 400 \mathrm{~mm}$ (height $\times$ width $\times$ length) was placed between the load cell and the prism to be tested. The failure mode of prisms subjected to compressive loading is due to vertical cracks and mortar crushing. The first crack arises in the face shell of the block (1), in the center line of the core, usually in both sides and close to $75 \%$ of peak load. Afterwards, the mortar joint crushes at some locations (2). The cracks in the blocks progress to the mortar joint. A vertical crack appears also in the middle of the transverse web (3) close the peak load, due to the lower stiffness of face-shell regions. Mortar crushing then progresses (4) and there are several cracks through the face-shells of prism at maximum test load (5). Generalized cracking with concrete spalling of the block is observed during the descending branch (6). The compression failure process, as indicated in the parenthesis above, is detailed in Fig. 4.

Table 2 summarizes the mean value of compressive strength of blocks $\left(f_{b}\right)$, mortars $\left(f_{m}\right)$ and prisms $\left(f_{p}\right)$ for each group (average results from three tests). The elastic and inelastic properties of concrete and mortar obtained from the tests are presented in Table 3, again as the average value from three tests. Here, $f_{c}$ is the compressive strength, $f_{t}$ is the tensile strength, $E$ is the elasticity modulus, $v$ is the Poisson ratio, $G_{f_{c}}$ is the fracture energy for compression and $G_{f}$ is the tensile fracture energy.

Young's moduli of materials were calculated considering the stress interval from 0 to $40 \%$ of the compressive strength. As an example, Fig. 5a depicts the stress-strain curve of a mortar sample of P1 group during the compressive test. The slope of the (continuous) secant line that connects the stress-strain point $0-0$ to the point defined by the horizontal dashed line at 0.4 
$f_{m}$ in longitudinal stress-strain diagram gives $E=9570 \mathrm{~N} / \mathrm{mm}^{2}$. The Poisson ratio is defined at the same stress level, considering the ratio between transversal and longitudinal strains. This parameter presents an approximately constant value of 0.127 until $0.4 f_{m}$, increasing with higher levels of compressive stress (Fig. 5b).

The areas under the curves considered for determination of $G_{f_{c}}$ and $G_{f}$ are depicted in Fig. 6.

It is noted that mortar crushing is more common in prisms P1 and P2 due their lower ratio between the elasticity modulus of mortar and concrete, in comparison with the same ratio in prisms $\mathrm{P} 3$ and $\mathrm{P} 4$, in which mortar crushing rarely occurred. For $\mathrm{P} 1$ and $\mathrm{P} 2$ groups, the ratio between the Young's modulus of mortar and concrete is about 0.47 and the difference in compressive strength is large, being failure due to crushing mortar. On other hand, P3 and P4 groups present a ratio between the Young's modulus and compressive strength of mortar and concrete about 0.61 , and the mortar joint did not crush.

\section{Numerical modeling}

The numerical simulations were carried out with continuum finite elements utilizing a micromodeling strategy, in which mortar and concrete are represented individually with nonlinear behavior. An incremental-iterative Newton-Raphson method with arc-length control and line-search technique was adopted to solve the resulting non-linear equilibrium equations (DIANA 2005). The load steps were adjusted manually, reducing the step size whenever divergence of the iterative process was found.

Three-dimensional analysis remains computationally very demanding and the use of simplified two-dimensional approaches is of relevance for the application of a numerical toolbox for strength prediction of hollow concrete masonry. Therefore, three different approaches were 
considered with respect to the out-of-plane conditions: plane-stress (PS), plane-strain (PE) and a three-dimensional (3D) analysis.

Fig. 7a depicts the basic cell defined to represent the prism and the one-eighth cell adopted for the numerical simulations (Fig. 7b). The boundary conditions assume symmetry, with the exception of the free edge, which is assumed without any constraint. The adopted simulation assumes that the friction effect of the loading platens is marginal, representing adequately the state of stress in the center block of the prism. The load was applied as a set of uniformly distributed displacements at the top of the quarter cell.

This approach is only phenomenological, in the sense that the numerical model cannot describe the micro-mechanical mechanisms involved in the failure mode of the real model. In addition, the splitting cracks, the boundary effects of the model and the failure modes are not symmetric in the tests, even if it is noted that these phenomena induce changes mainly in the post-peak behavior.

The two-dimensional mesh includes 704 eight-noded quadrilateral elements (totaling 2221 nodes), with quadratic interpolation and 3x3 Gauss integration. The three-dimensional mesh includes 968 twenty-noded brick elements (totaling 6429 nodes), with a quadratic interpolation and $3 \times 3 \times 3$ Gauss integration. Fig. 8 shows the finite element mesh utilized in the three-dimensional analysis. It is noted that a coarse discretization is assumed in the transverse direction, i.e. in the region of transverse block webs. This is due to the fact that experimental results indicate that failure mechanisms in the longitudinal direction (or face shells) mostly control the response. In the figure, $x$ is the longitudinal direction and $z$ is the transverse direction. The results obtained will be shown always using the full cell in order to allow a better understanding, by post-processing the results for the one-eighth using the symmetry conditions. 
For plane stress analysis, a composite plasticity model using the Drucker-Prager and Rankine criteria describes the behavior of material under compression and tension. Inelastic behavior presents a hardening-softening parabolic diagram in compression and an exponential softening diagram in tension. For three-dimensional analysis, Drucker-Prager was combined with a smeared cracking with a straight tension cut-off, exponential tension softening and variable shear retention. Details about the models can be found in Rots (1988) and Feenstra (1993). .A friction angle $\phi=10^{\circ}$ (DIANA 2005; Lourenço and Pina-Henriques 2006) and dilatancy angle $\psi$ $=5^{\circ}$ was adopted (Vermeer and de Borst 1984). With the exception of these values, all other values requested by the constitutive models have been outlined in detail in the previous section, obtained directly via experimental testing. It is noted that the value of the friction angle given above yields correct results for biaxial loading (an increase of strength about 10-25\%) and a larger value is not recommended for applications unless the value of the three principal stresses are comparable. The value of the dilatancy angle has minor influence in the results, as confirmed by tests using associated flow.

Each approach corresponds to a different out-of-plane confining level. In plane stress (PS) approach the out-of-plane deformation is not restrained and the specimen can deform freely. On the contrary, out-of-plane deformation is fully restrained in the plane strain (PE) approach. In reality, the test conditions induce an intermediate state of stress in the prism, between these extreme conditions, closely represented by the three-dimensional model (3D).

\section{Stress-strain diagrams}

The stress-strain diagrams obtained for all numerical simulations are shown in Fig. 9, as well as experimental results. It is noted that the numerical analysis was terminated soon after the peak load, as experimental results were often not available due to explosive uncontrolled failure 
of the prism and also the cost of carrying out the numerical analysis until complete failure. Once significant inelastic behavior occurs, non-linear analysis tends to lead to increasing convergence difficulties. The theoretical compressive strength is lower than the experimental value for all models in PS approach. The PE approach provides the maximum theoretical stress, higher than the one reached in the experimental tests. A good estimation of the peak load is obtained from 3D analysis, being the numerical values similar to experimental values (maximum difference of $20 \%$ and average difference of $10 \%)$. It is noted that, in the case of 3D analysis, prisms P1 and P2 presented serious convergence problems due the non-homogeneous stresses induced by large differences in the mechanical properties of mortar and block. Table 4 summarizes the ultimate load reached in the analyses, comparing the numerical and experimental results. Here, the experimental ultimate load is represented by the average results from the tests in three prisms.

The lower values of ultimate load were obtained in PS approach due to the absence of the confinement effect that induces premature failure of the mortar joint. The numerical values are between $60 \%$ and $80 \%$ of the experimental data values. The PE approach does not allow displacements in direction orthogonal to the plane of analysis, inducing excessive triaxial effects in the mortar joint, whereas the concrete block is in a compression-tension biaxial state. Consequently, too high ultimate load values are obtained in all prism models, with an average increase of about $40 \%$ in comparison with the experimental values.

A good accuracy in the linear branch of the stress-strain diagram for the three approaches is also found. PS and 3D approaches have also a satisfactory behavior in the cracked phase as the reduction of stiffness agrees well with the experimental results up to $80 \%-90 \%$ of the ultimate load. 
In spite of the fact that the 3D approach provided adequate ultimate load values, with the exception of prism P4, the peak strain value is only about $60 \%$ of the experimental value. Even worse agreement is found for the PS approach, whereas oscillating values (both above and below the experimental values) are obtained in terms of PE. Table 5 shows a comparison of all peak strain values.

This result seems to indicate that, for levels of very high damage, the adopted continuum models are inadequate to simulate the response. The possibilities would be to change the volumetric response using variable dilatancy or to adopt particulate models that more closely represent micro-mechanical effects at failure (Pina-Henriques and Lourenço 2006).

\section{Lateral Strains}

Fig. 10a depicts the resultant lateral stresses, as the average value obtained along of the length of bed joint, development of mortar joint in PS and PE approaches. The reference line of these values is located in the middle height of mortar joint, indicated by the dashed line in the figure. Lateral confinement is found in PS and PE approaches. The effect is more severe and quasi-linear in the PE approach, whereas for PS lateral confinement becomes more relevant only for very large stresses (about $90 \%$ of the failure load). The horizontal stress distribution along the mortar joint (also related to the dashed line of Fig. 10a) is represented in Fig. 10b, where lateral stresses are related to the vertical load at distinct levels, defined in accordance to stress-strain relationship behavior. The vertical load of $30 \%$ and $40 \%$ represents roughly the limits of linear branch for PS and PE approaches, respectively, and the vertical load of $100 \%$ corresponds to the failure stress in both analyses. The higher values of confinement occur in the face-shell / transversal web regions or in their vicinity. The higher intensive confinement effect in PE approach is also clearly indicated. 


\section{Failure Patterns}

Fig. 11 depicts the failure pattern and deformed mesh of the basic cell, of relevance to appraise the adequacy of the numerical analysis. Mortar crushing in bed joint causes the prism failure when the PS approach is adopted. No significant cracks are identified in the blocks and mortar crushing occurs in the full development of the joint.

Mortar crushing is again detected in the PE approach, but diagonal cracks in the blocks are identified also. Cracking is due to the block deformation restraint in the out-of-plane direction and mortar crushing occurs intensively only in the face shell / external transversal web region.

The failure mode presented in three-dimensional analyses is closer to experimental tests, with the development of vertical cracks through the blocks and crushing of bed joint mortar. It must be emphasized that the failure mode depends on the model strategy adopted, being numerically correct but non-fully realistic, due to the limitations of continuum finite element modeling.

\section{$3 D$ aspects}

A detailed analysis of the 3D model indicates that the model predicts non-linear behavior of the concrete block and mortar joint with severe stress redistributions under increasing compression, inducing a triaxial state in the mortar joint and a compression-tension state in the blocks.

The block and mortar resistant stress-strain diagrams are presented in Fig. 12. The tensile strength of concrete is reached, represented by the large increase of the lateral strain close to peak load in Fig. 12a. On the other hand, Fig. 12b indicates that the block would still support 
compressive load in the absence of transverse cracking and the mortar presents very high longitudinal strain values, due to triaxial effect that acts in the bed joint (Barbosa et al. 2006).

For further discussion, Figs. 13 and 14 present the stress and strain distribution in prism P4 at failure, using incremental deformed meshes. The higher minimum (compressive) plastic strains are identified in the mortar joint due to the triaxial effect, contrasting with the low values obtained in the blocks (Fig. 13a). The higher absolute values of minimum (compressive) principal stresses, depicted in Fig. 13b, are found in the external and central transversal webs and the lower ones occurs in the hollow central part of the block, indicating a load redistribution from the central part of the block to the transverse webs. In the central part of the block, very high values of maximum (tensile) principal strains are found due to cracking (Fig. 13c).

The intensity of minimum (compressive) principal stresses is also high in the central part of transversal webs, near the mortar joints, as shown in Fig. 14, indicating the full threedimensional effect at failure.

\section{Conclusions}

Laboratory tests using specially made hollow concrete blocks allowed to adequately characterize the block mechanical properties by specimen testing. Similarly, the mortar properties were obtained from specimen testing. Tests on masonry prisms with four different combinations of block/mortar strength indicate that the resulting failure modes are associated with the differences between the mechanical properties of concrete and mortar. Failure is associated with vertical cracks and/or mortar crushing, depending on the mechanical properties of masonry components and the ratio between block and mortar strength.

The proposed strategy allowed to obtain the elastic and inelastic parameters needed for advanced non-linear numerical simulations. Therefore, the present paper addresses the ability of 
numerical methods using continuum models, based on plasticity and smeared cracking, to reproduce the experimental compressive behavior of hollow concrete block masonry prisms. The comparison between numerical and experimental results allows to conclude that distinct approaches lead to different strength, different failure mechanisms and different force-strain diagrams.

The plane-stress modeling approach does not consider the restraint of materials in the out-of-plane direction, which induces premature failure of the bed mortar joint and too conservative results in terms of failure load. The plane-strain modeling approach does not allow displacements in the out-of-plane direction, which provides non-conservative results in terms of failure load and changes the failure mode from mortar crushing to diagonal cracks in the blocks.

Three-dimensional numerical modeling predicts ultimate loads and failure patterns in accordance with the experiment results, with a combination of vertical cracks and mortar crushing failure. Only the deformation capacity above $80-90 \%$ of the ultimate load could not be correctly reproduced by the model, which is often not relevant for engineering applications.

\section{Acknowledgements}

The authors would like to acknowledge FAPESP - Sao Paulo State Research Support Foundation - and CAPES - Brazilian Research Support Foundation - for the financial support given to this research. 


\section{References}

American Society for Testing and Materials (2007). ASTM C 150: Standard Specification for Portland cement. 2007.

Barbosa, C.S. (2004). "Strength and deformability of hollow concrete blocks and their correlation to mechanical properties of constituent material." MSc Thesis, University of Sao Paulo, Sao Carlos, Brazil. 153p. Available from <http://www.set.eesc.usp.br/public/teses> (in Portuguese).

Barbosa, C.S., Lourenço, P.B., Mohamad, G., and Hanai, J.B. (2007). “Triaxial compression tests on bedding mortar samples looking at confinement effect analysis." Proceedings of the 10th North American Masonry Conference, St. Louis, Missouri, USA, 992-1002.

DIANA (2005). "Finite Element Code: User's Manual - Release 9.” TNO Building and Construction Research: Delft, The Netherlands.

Feenstra P. (1993). "Computational Aspects of Biaxial Stress in Plain and Reinforced Concrete”. PhD thesis. Delft University of Technology, The Netherlands.

Frasson Junior, A.F. (2000). "Methodology for sampling and manufacturing process control for concrete blocks structural masonry." MSc Thesis, Federal University of Santa Catarina, Florianopolis, Brazil. 146p. (in Portuguese).

Ganzerli, S. et al. (2003). "Compression strength testing for nonstandard concrete masonry units." Proceedings of the North American Masonry Conference, 9., Clemson, South Carolina, USA, 60-71.

Hamid, A.A., and Chukwunenye, A.O. (1986). "Compression behavior of concrete masonry prisms.” Journal of Structural Engineering, 112(3), 605-13. 
Hawk, S.W., McLean, D.I., and Young, T.C. (1997). "Compressive behavior of insulated concrete masonry prisms.” The Masonry Society Journal, 15(2), 53-60.

Koksal H.O., Karakoc C., Yidirim H. (2005). "Compression behavior and failure mechanisms of concrete masonry prisms.” Journal of Materials in Civil Engineering, 17(1), 107-115.

Lourenço, P.B. (1996). “Computational strategies for masonry structures.” Delft University Press: The Netherlands. 210p. Available from < www.civil.uminho.pt/masonry>.

Lourenço, P.B., Pina-Henriques, J.L. (2006). "Masonry micro-modelling: a continuum approach in compression.” Computers \& Structures, 84(29-30), 1977-1989.

Marzahn, G.A. (2003). "Extended investigation of mechanical properties of masonry units." Proceedings of the North American Masonry Conference, 9., Clemson, South Carolina, USA, 813-824.

Page A.W., Shrive N.G. (1990). "Concentrated loads on hollow concrete masonry." ACI Structural Journal, 87 (4), 436-444.

Pina-Henriques, J.L., Lourenço, P.B. (2006). "Masonry compression: a numerical investigation at the meso-level." Engineering Computations, 23(4), 382-407.

RILEM (1985). TC 50-FMC: "Determination of the fracture energy of mortar and concrete by means of three-point bend tests on notched beams." Materials and Structures, 18(4), 287-290.

Rots JG. (1988). “Computational Modeling of Concrete Fracture”. PhD thesis. Delft University of Technology, The Netherlands.

SayedAhmed E.Y., Shrive N.G. (1996). "Design of face-shell bedded hollow masonry subject to concentrated loads." Canadian Journal of Civil Engineering, 23 (1), 98-106. 
Stöckl, S., Bierwirth, H., and Kupfer, H. (1994). "The influence of test method on the results of compression tests on mortar." Proceedings of the $10^{\text {th }}$ International Brick and Block Masonry Conference, Calgary, Alberta, Canada.

Vermeer, P.A., and de Borst, R. (1984). "Non-associated plasticity for soils, concrete and rock." Heron, 29(3), 1-64. 


\section{List of figures}

Fig. 1. Hollow concrete block with dimensions in centimeters and the steel mold to cast the blocks.

Fig. 2. Three block stack-bond prism, mortar specimens and lay-out of the compression test on prisms.

Fig. 3. Manufacturing of concrete beam and mortar sample.

Fig. 4. Failure process: (a) Evolution of cracking in blocks and mortar crushing - dashed line indicates initial cracking, continuous line indicate the final cracking pattern and dark spots indicate mortar crushing; (b) details of cracking and crushing.

Fig. 5: Young's modulus and Poisson ratio defined on the stress-strain behavior of the tests (a). Behavior of Poisson ratio under compressive test (b).

Fig. 6: Area under stress-strain curve considered to calculate $G_{f_{c}}$ (a) and area under forcedisplacement curve considered to calculate ${ }^{G_{f}}$ (b).

Fig. 7. Three block high masonry prism (dimensions in $\mathrm{mm}$ ), a basic cell and one-eighth of a basic cell are indicated: (a) basic cell; (b) one-eighth cell utilized in the numerical simulations.

Fig. 8. Different views of the finite element mesh corresponding to a one-eighth of basic cell.

Fig. 9. Stress-strain experimental and numerical diagrams.

Fig. 10. Mortar confinement in the longitudinal direction: (a) Evolution with loading; (b) Confinement through the length of mortar joint.

Fig. 11. Failure patterns on the incremental deformed mesh. 
Fig. 12. Stress-strain diagrams: (a) lateral strain for block measured at mid-height of block; (b) average vertical strain for block, mortar and prism, measured in the net area.

Fig. 13. Results for prism P4 at failure, plotted in the deformed mesh: (a) Minimum principal plastic strain $\left(\mathrm{N} / \mathrm{mm}^{2}\right)$; (b) Minimum principal stresses $\left(\mathrm{N} / \mathrm{mm}^{2}\right)$; (c) Maximum principal strains.

Fig. 14. Minimum principal stresses for the transverse webs, for prism $\mathrm{P} 4$ at failure $\left(\mathrm{N} / \mathrm{mm}^{2}\right)$ 


\section{List of tables}

Table 1. Concrete and mortar mix proportions (in volume).

Table 2. Compressive strength of blocks $(b)$, mortar $(m)$ and prisms $(p)$. Value in parenthesis indicates the coefficient of variation (three tests have been performed for each material property).

Table 3. Comparison between the numerical and experimental ultimate stress, for the four mortar-block sets. Here, PS indicates plane stress, PE indicates plane strain and 3D indicates three-dimensional model.

Table 4. Comparison between the numerical and experimental ultimate stress, for the four mortar-block sets. Here, PS indicates plane stress, PE indicates plane strain and 3D indicates three-dimensional model.

Table 5. Comparison of theoretical and experimental peak strain values in distinct analyses. $\mu$ indicates microns, i.e. that the values should be multiplied by $10^{-6}$. 

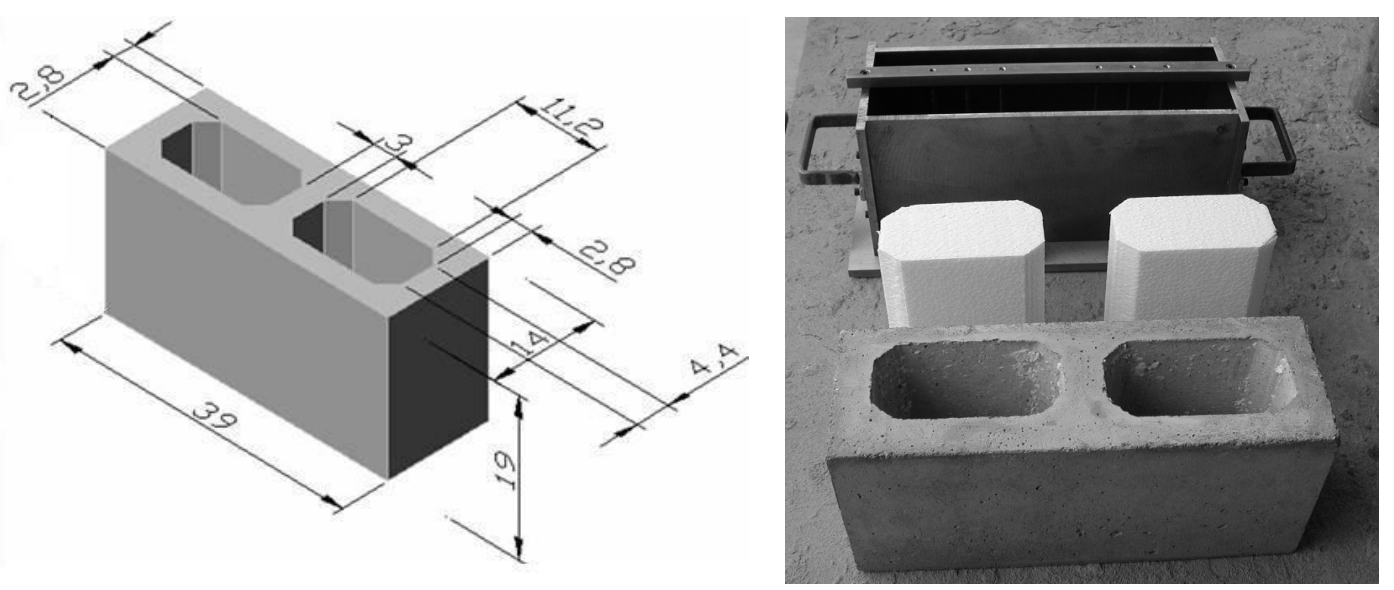

Fig. 1. Hollow concrete block with dimensions in centimeters and the steel mold to cast the blocks. 

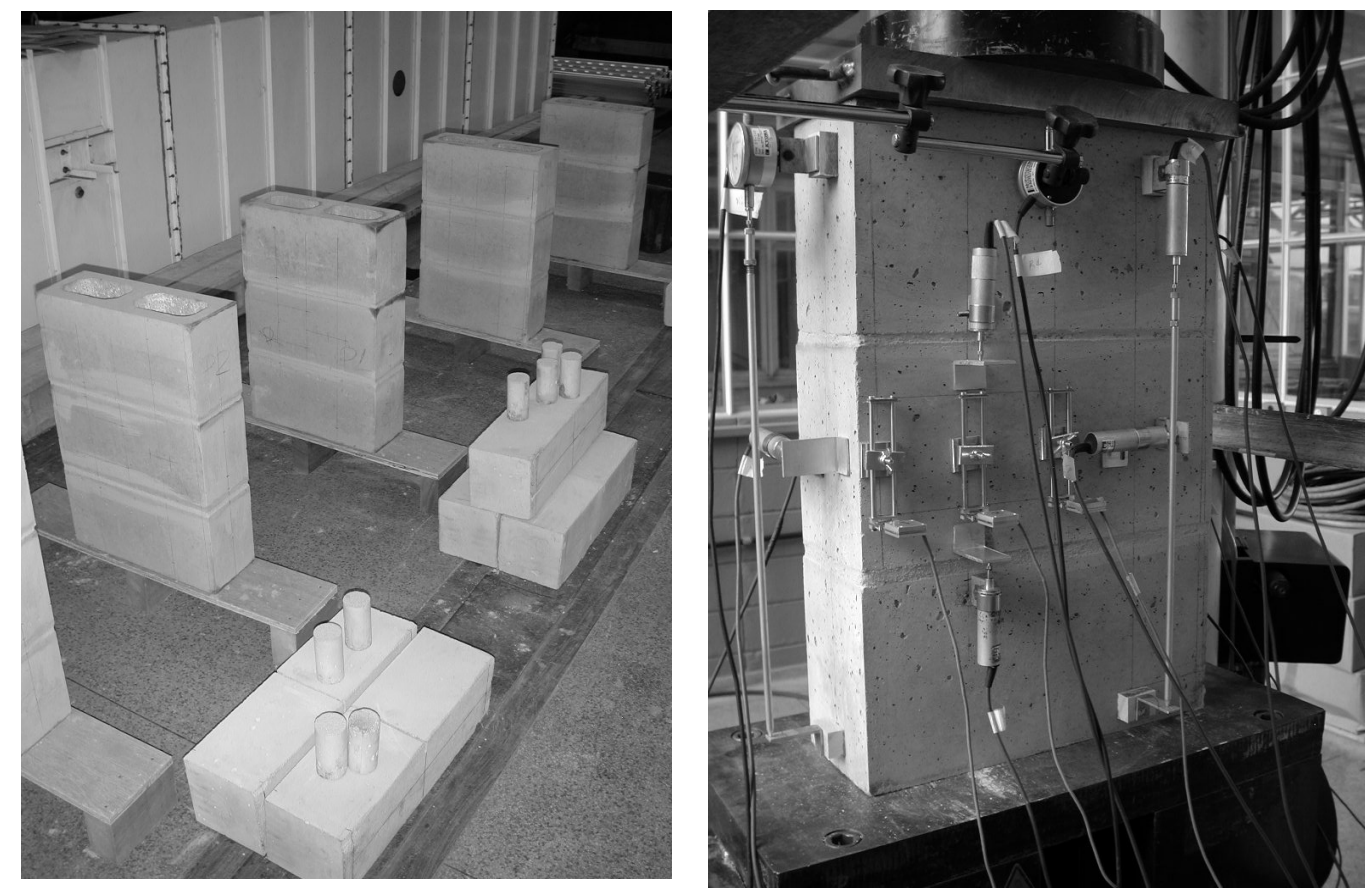

Fig. 2. Three block stack-bond prism, mortar specimens and lay-out of the compression test on prisms. 

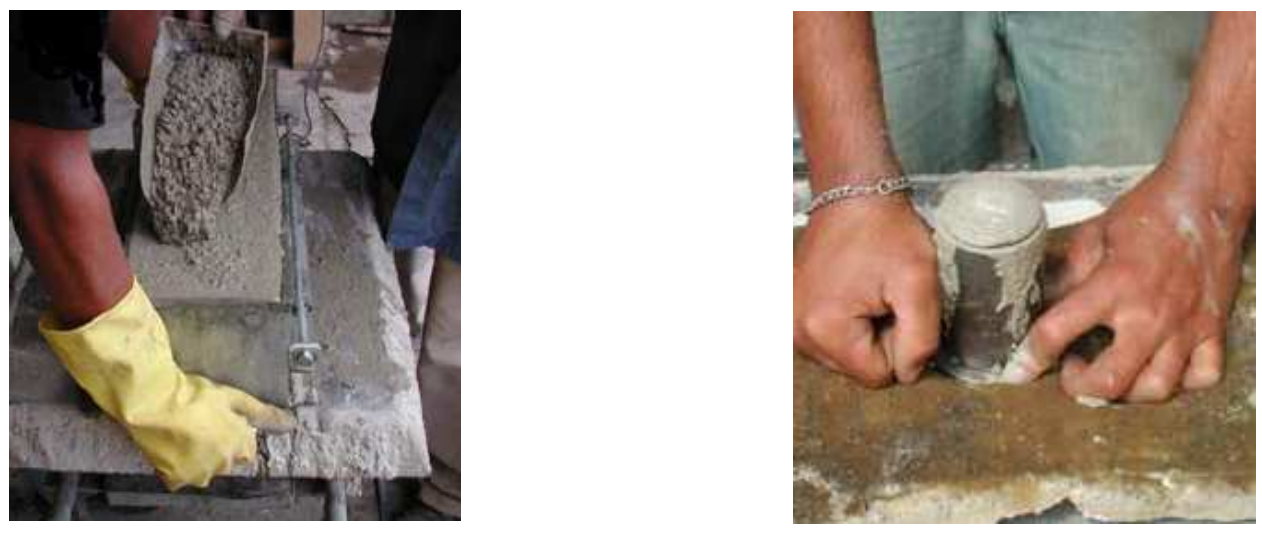

Fig. 3. Manufacturing of concrete beam and mortar sample. 

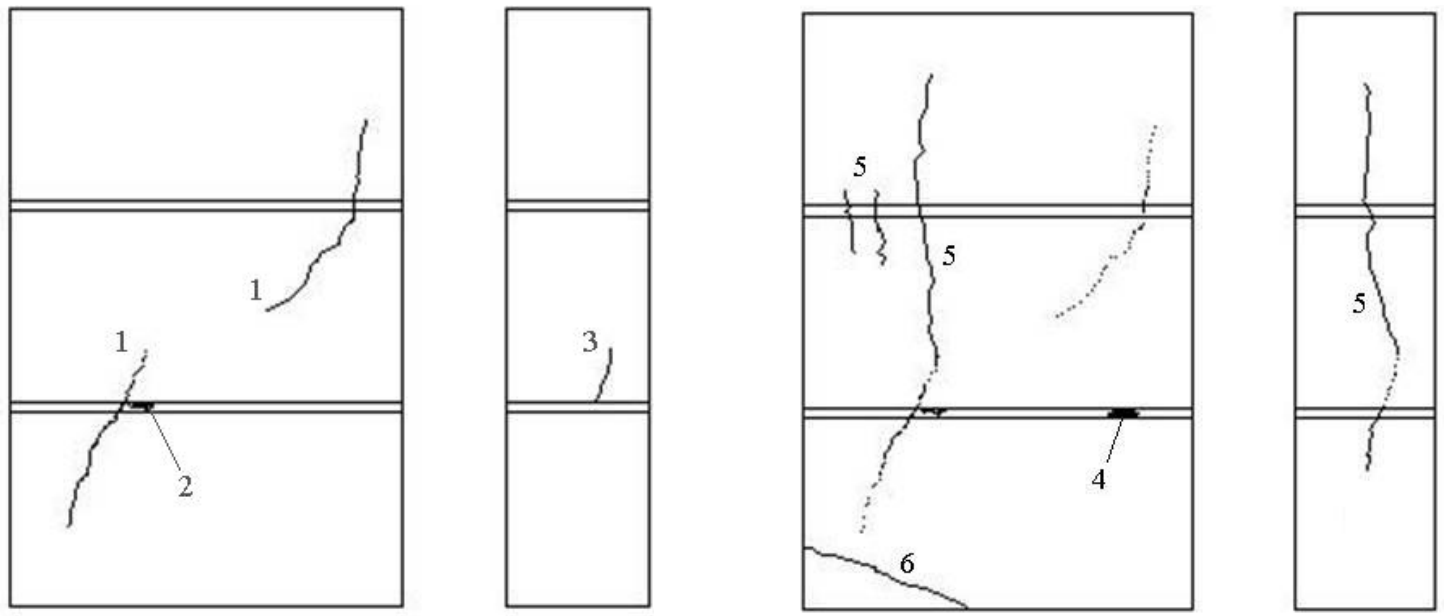

(a)
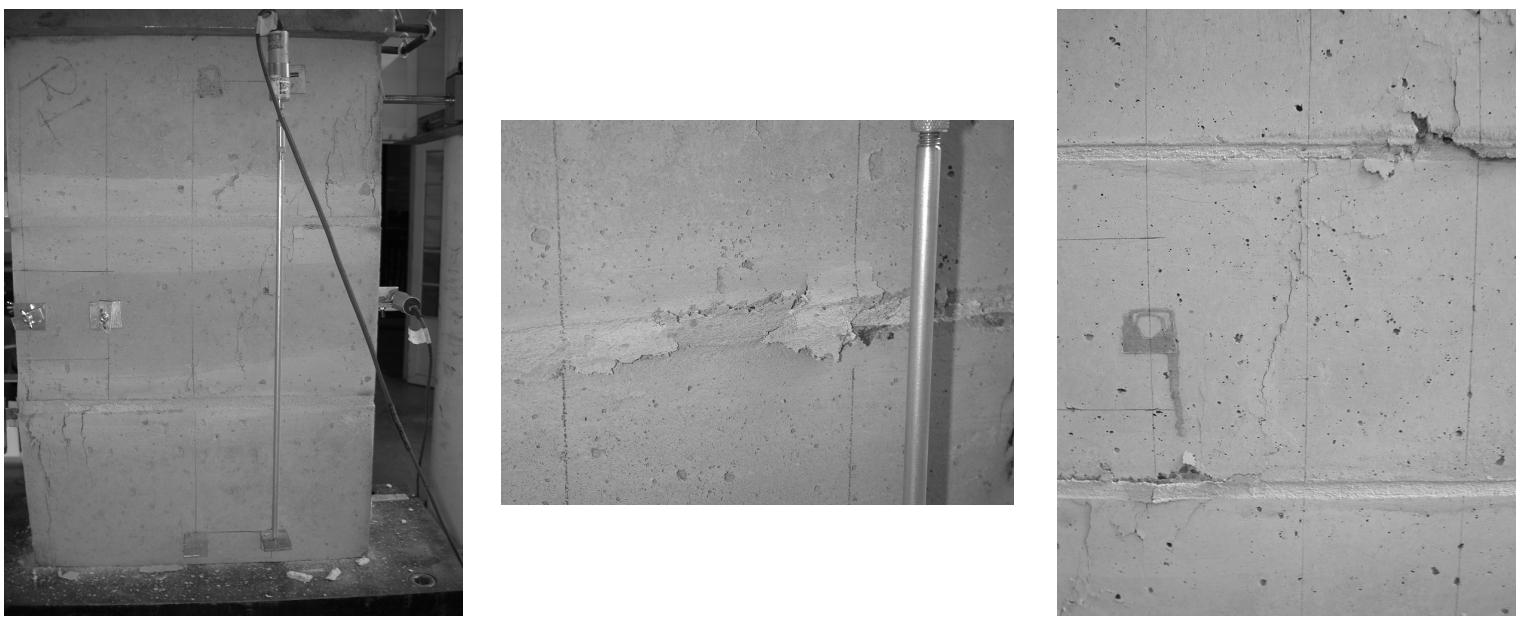

(b)

Fig. 4. Failure process: (a) Evolution of cracking in blocks and mortar crushing - dashed line indicates initial cracking, continuous line indicate the final cracking pattern and dark spots indicate mortar crushing; (b) details of cracking and crushing. 


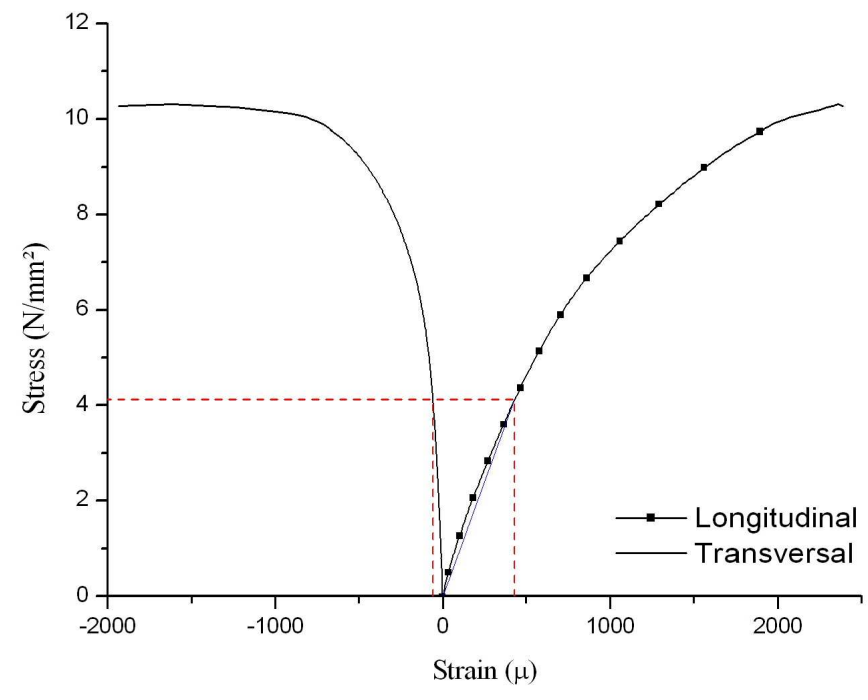

(a)

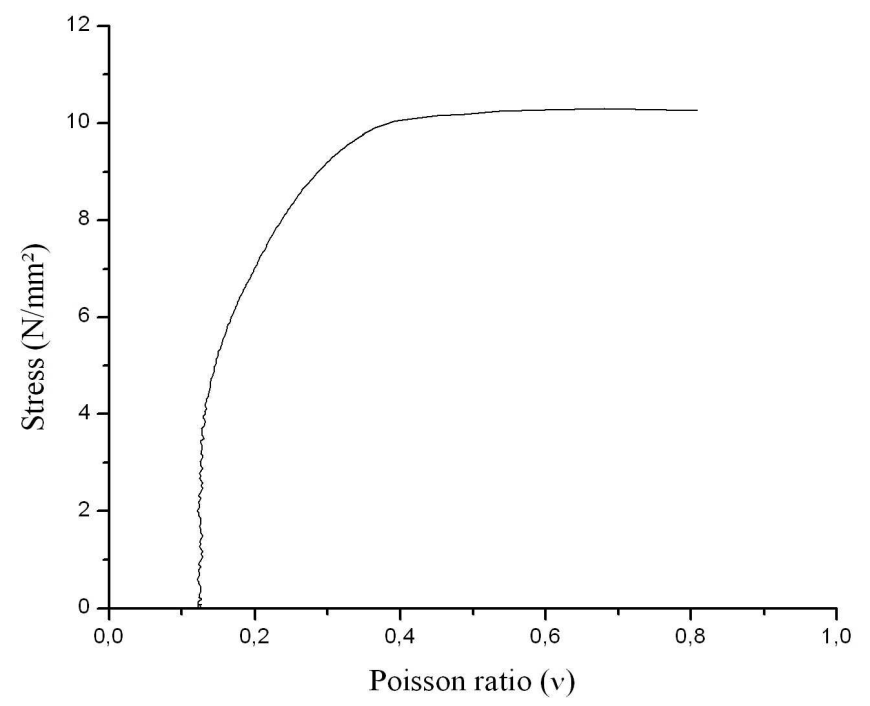

(b)

Fig. 5. Young's modulus and Poisson ratio defined on the stress-strain behavior of the tests (a). Behavior of Poisson ratio under compressive test (b). 


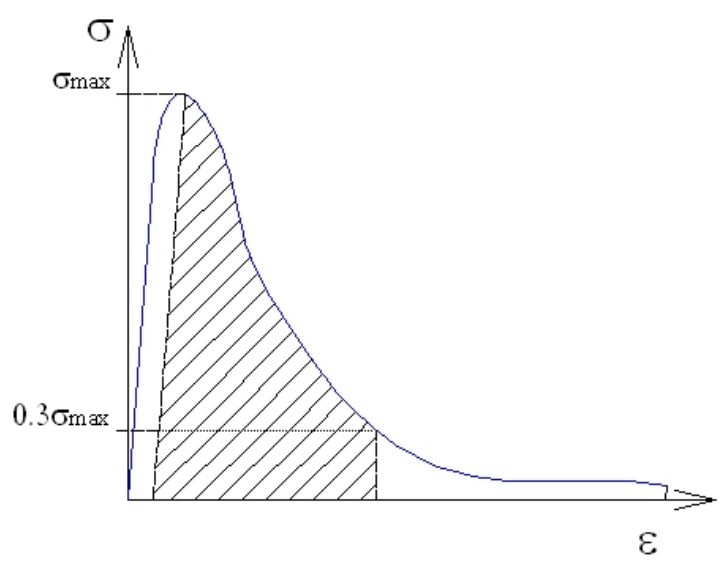

(a)

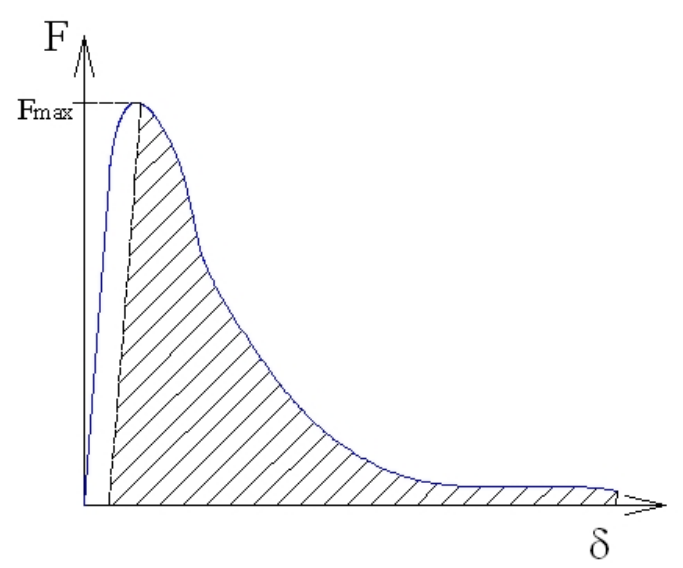

(b)

Fig. 6. Area under stress-strain curve considered to calculate $G_{f_{c}}$ (a) and area under forcedisplacement curve considered to calculate $G_{f}(\mathrm{~b})$. 


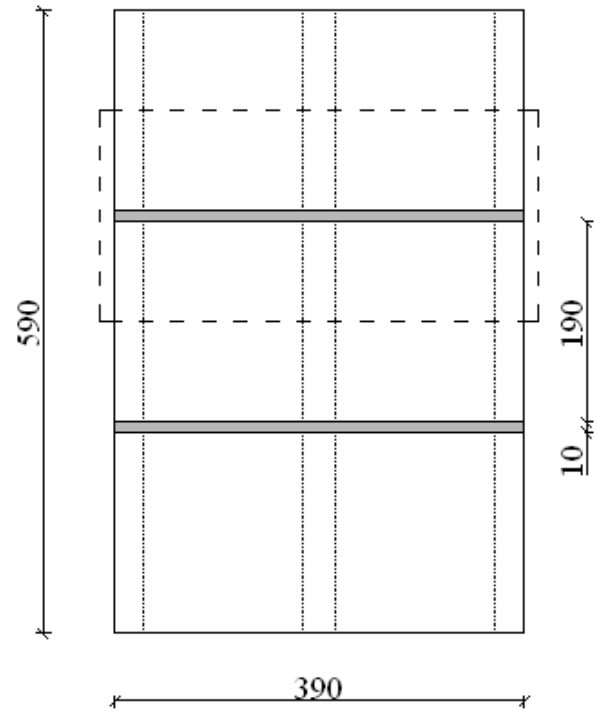

(a)
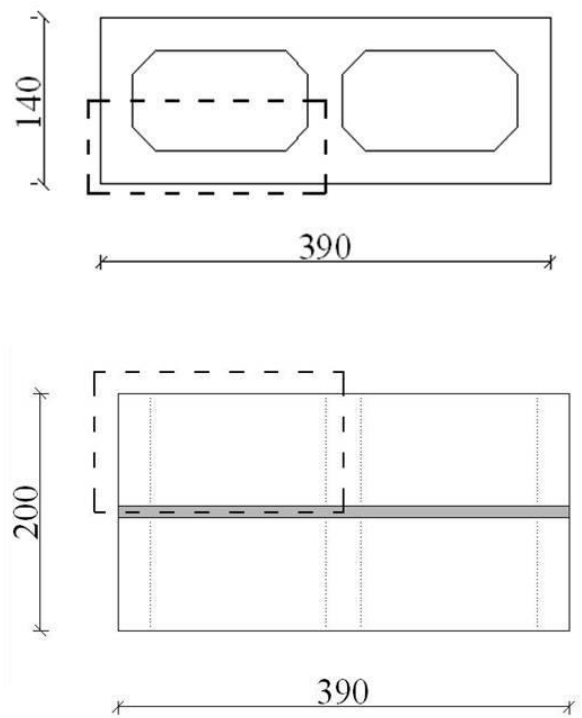

(b)

Fig. 7. Three block high masonry prism (dimensions in $\mathrm{mm}$ ), a basic cell and one-eighth of a basic cell are indicated: (a) basic cell; (b) one-eighth cell utilized in the numerical simulations. 

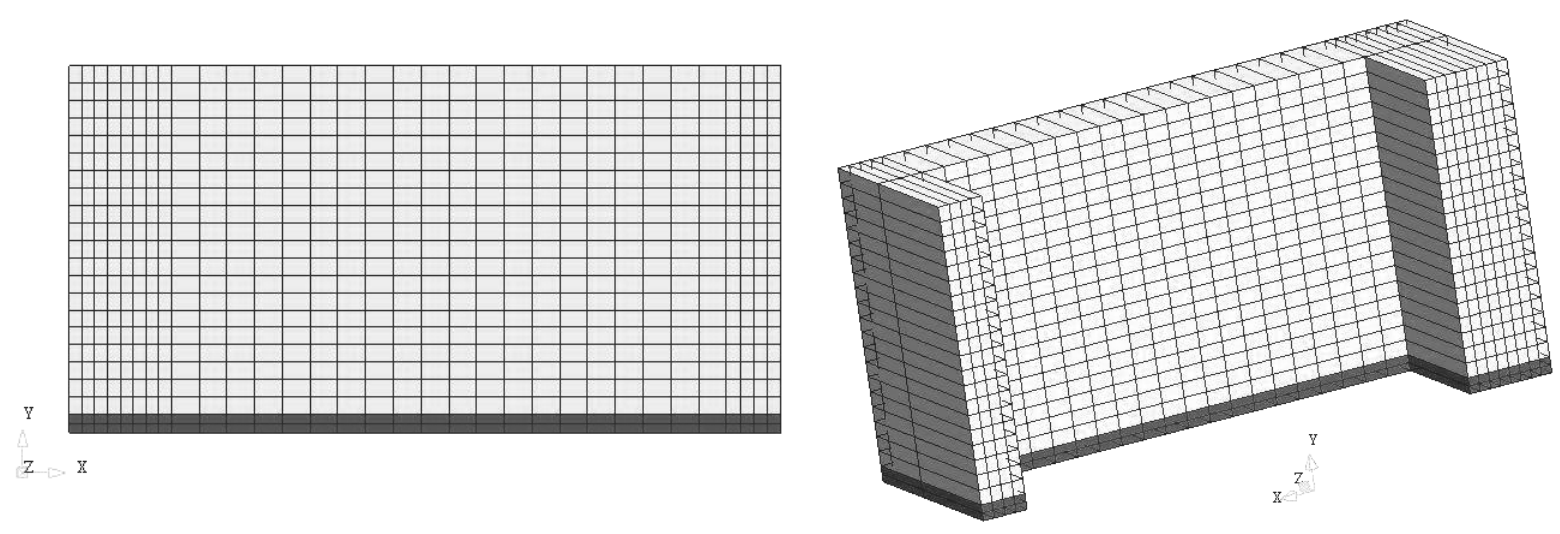

Fig. 8. Different views of the finite element mesh corresponding to one-eighth of basic cell. 


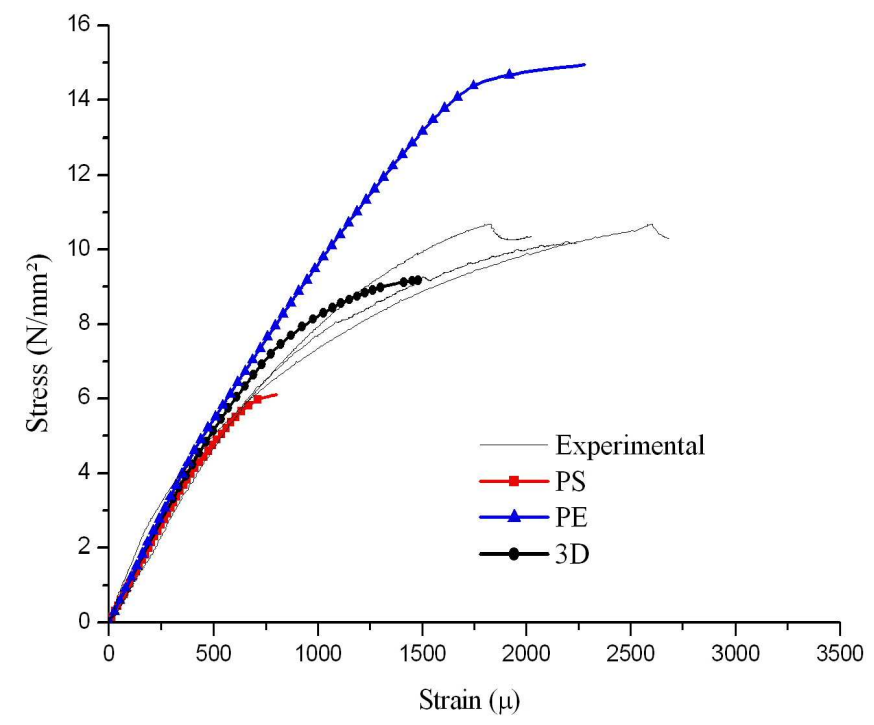

P1

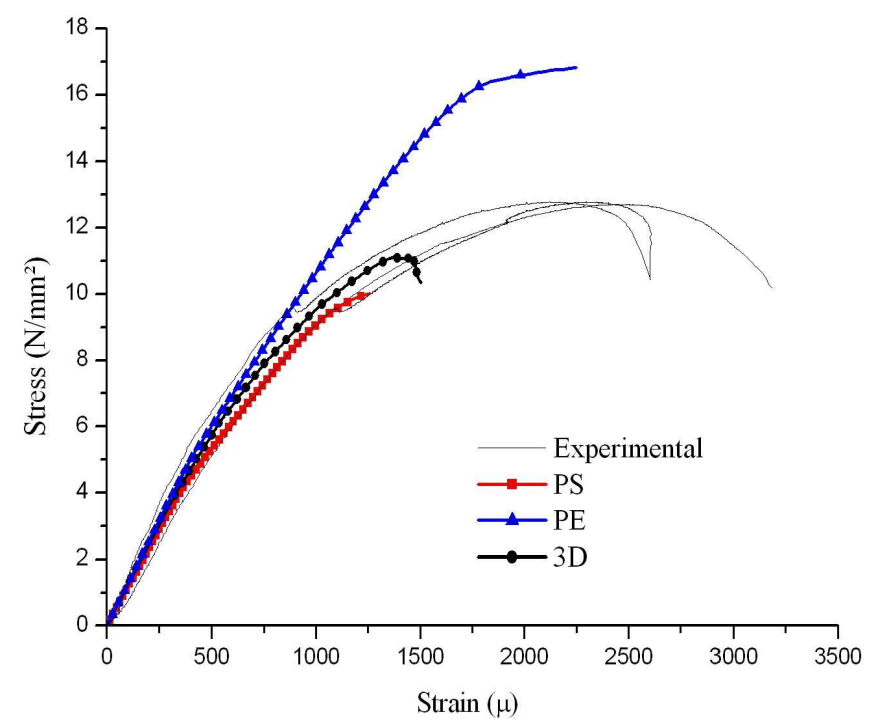

P3

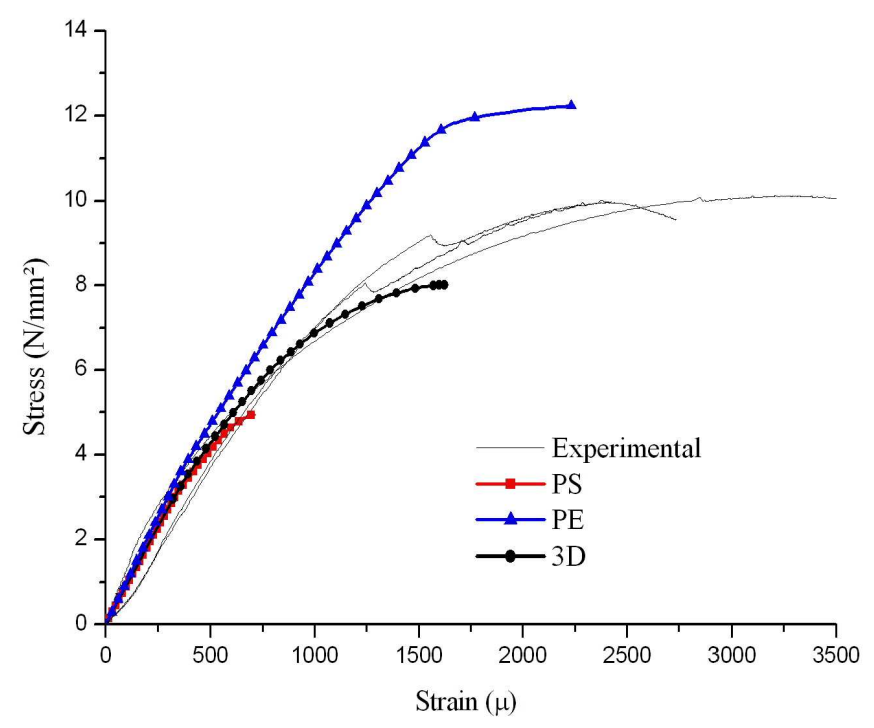

P2

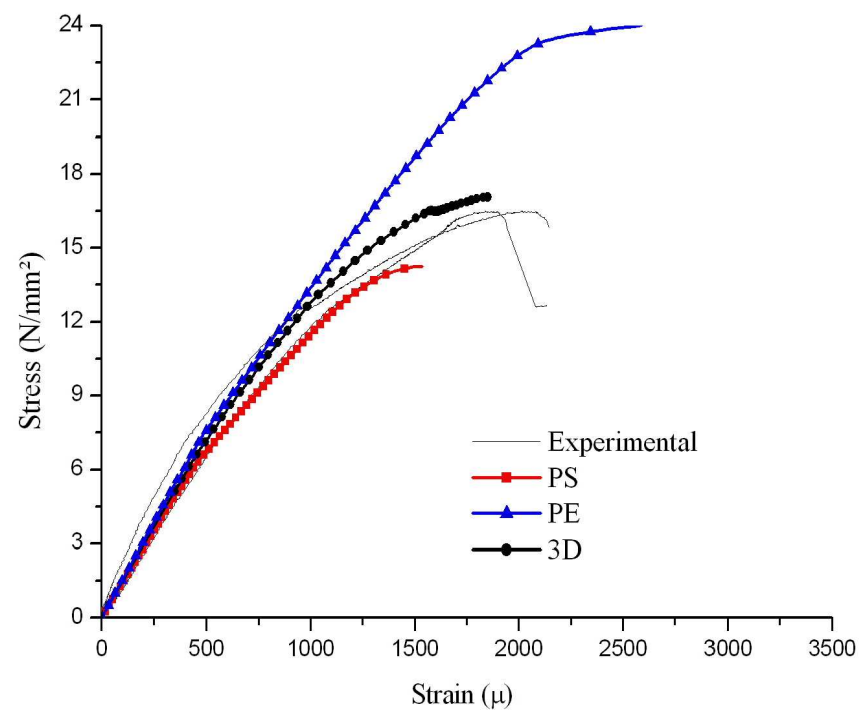

P4

Fig. 9. Stress-strain experimental and numerical diagrams. 


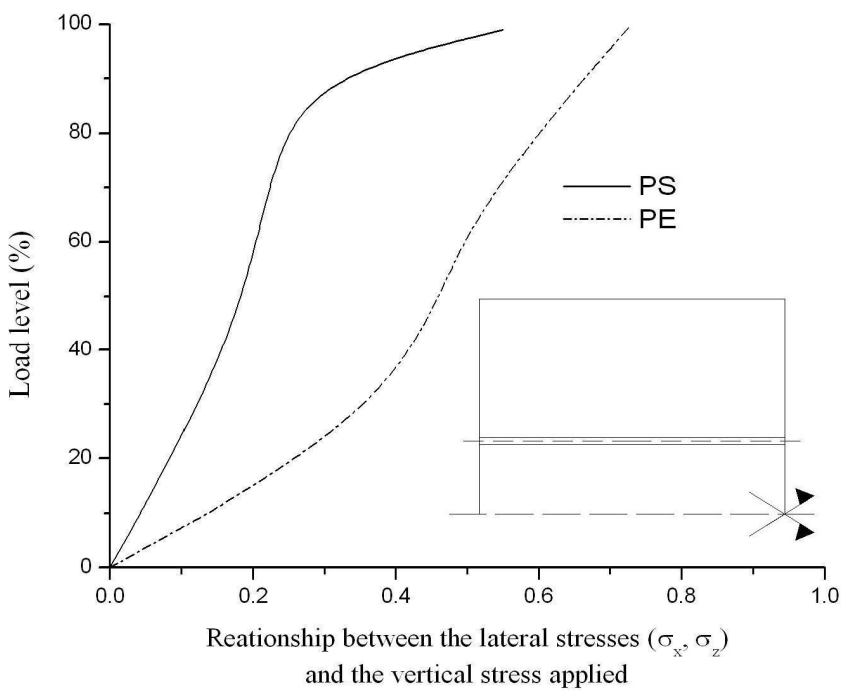

(a)

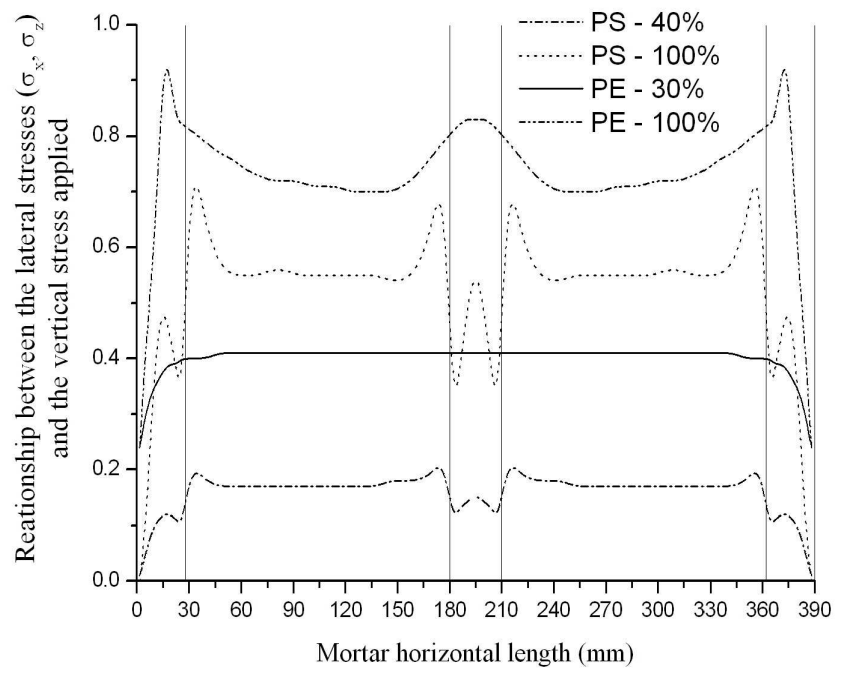

(b)

Fig. 10. Mortar confinement in the longitudinal direction: (a) Evolution with loading; (b) Confinement through the length of mortar joint. 


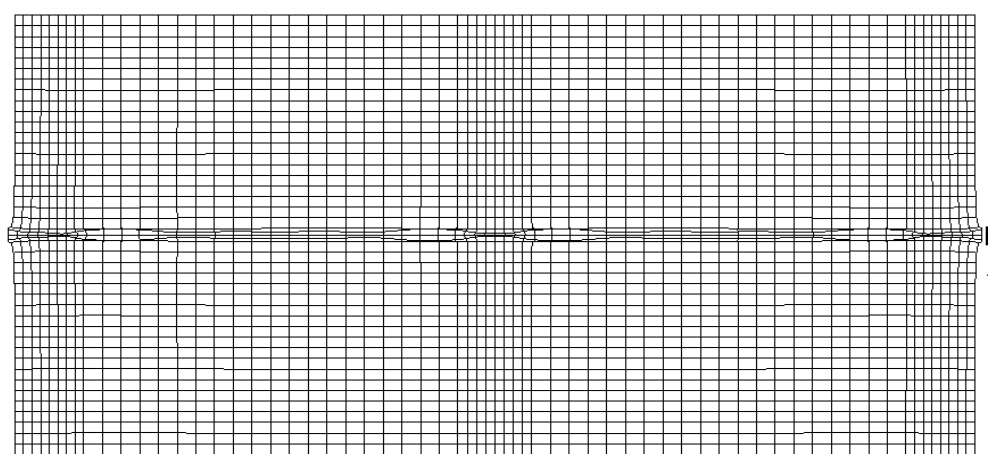

PS
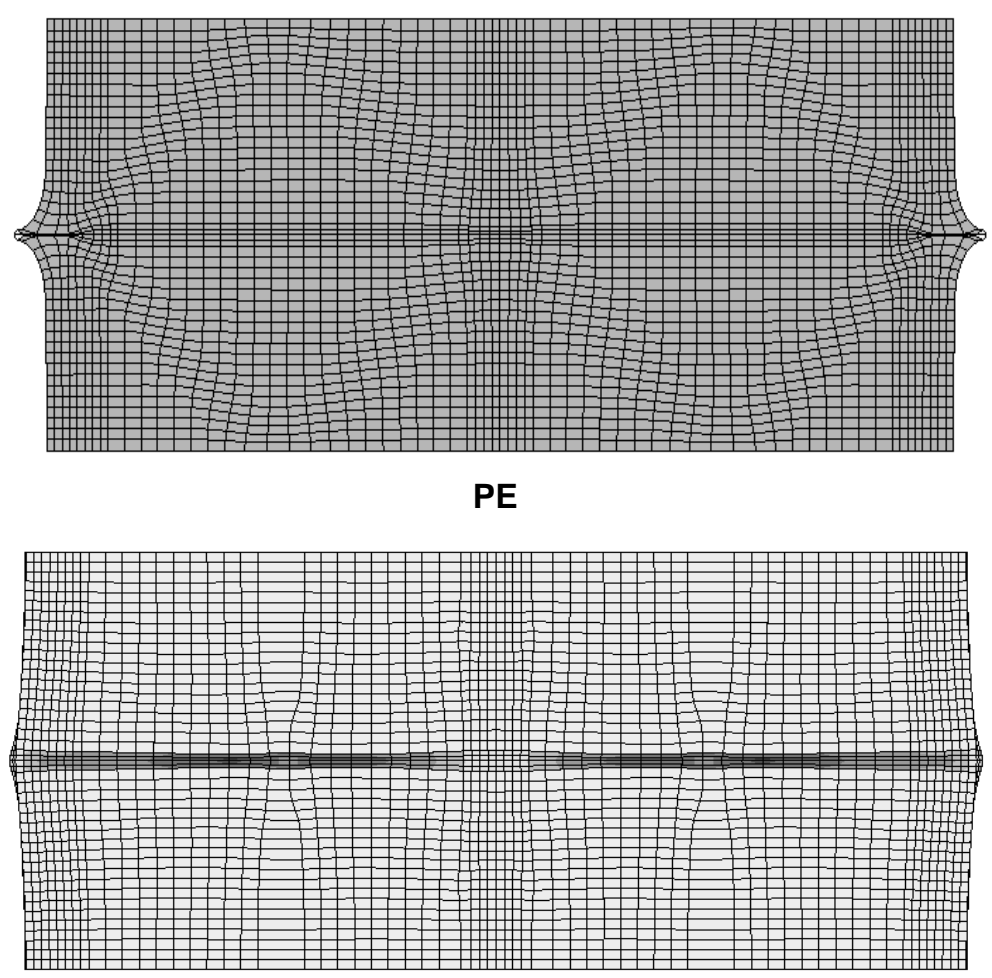

3D

Fig.11. Failure patterns on the incremental deformed mesh. 


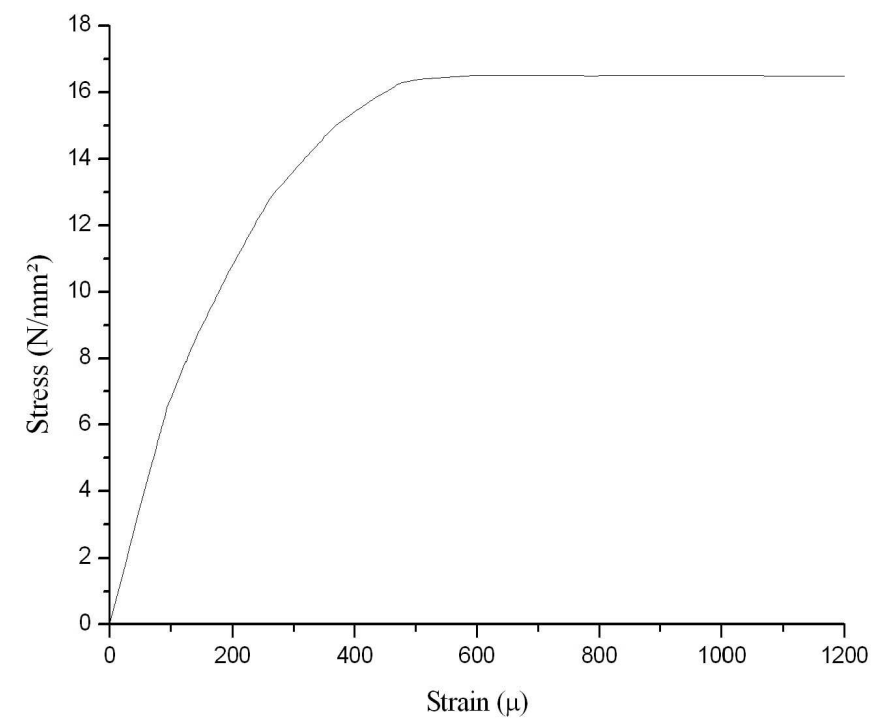

(a)

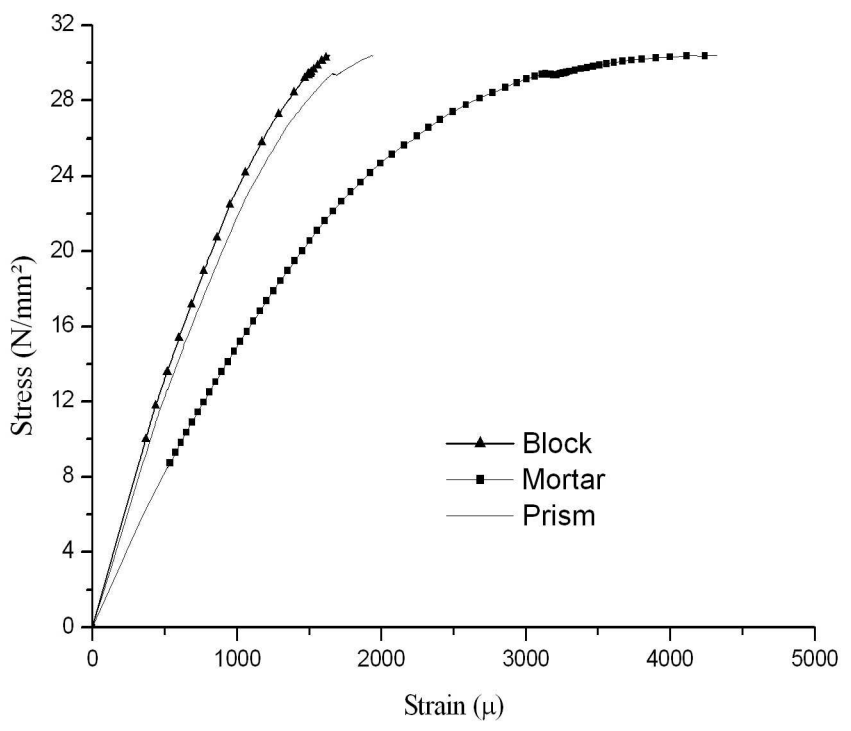

(b)

Fig. 12. Stress-strain diagrams: (a) lateral strain for block measured at mid-height of block; (b) average vertical strain for block, mortar and prism, measured in the net area. 

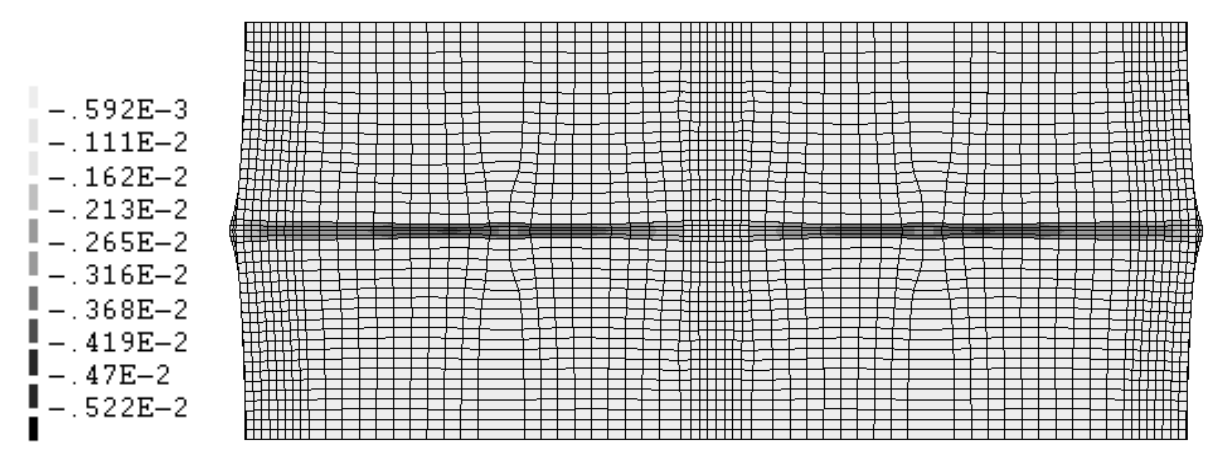

(a)

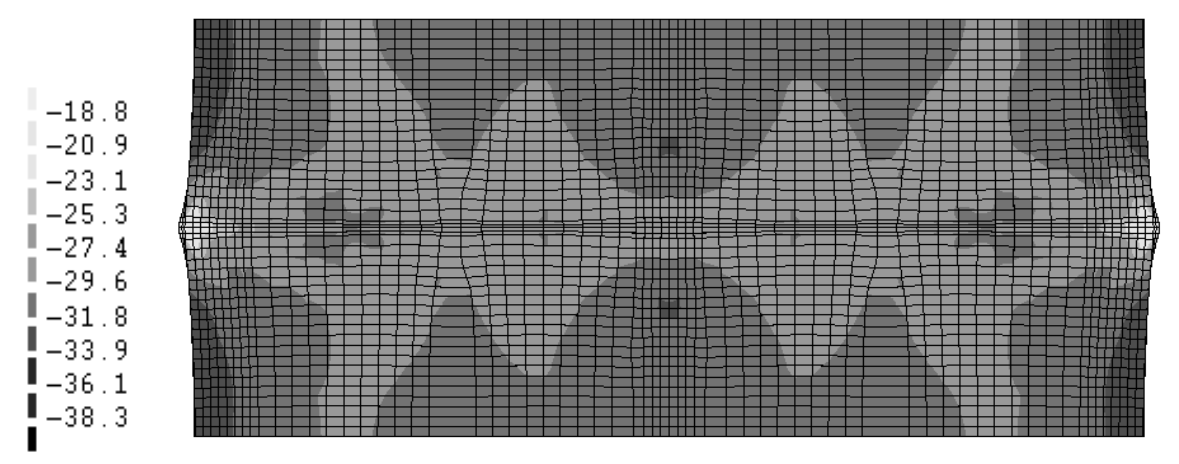

(b)

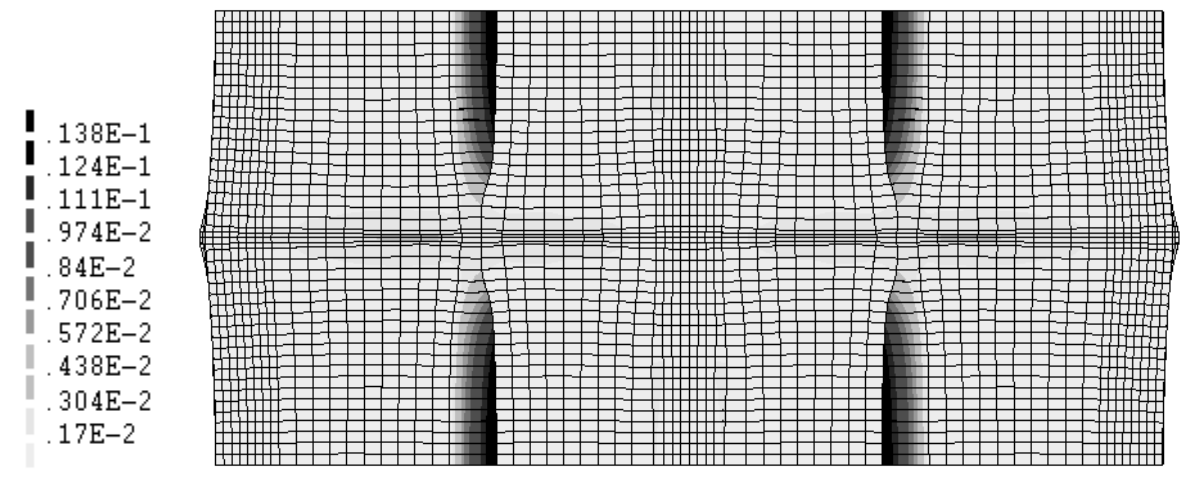

(c)

Fig. 13. Results for prism $P 4$ at failure, plotted in the deformed mesh: (a) Minimum principal plastic strain $\left(\mathrm{N} / \mathrm{mm}^{2}\right)$; (b) Minimum principal stresses $\left(\mathrm{N} / \mathrm{mm}^{2}\right)$; (c) Maximum principal strains. 


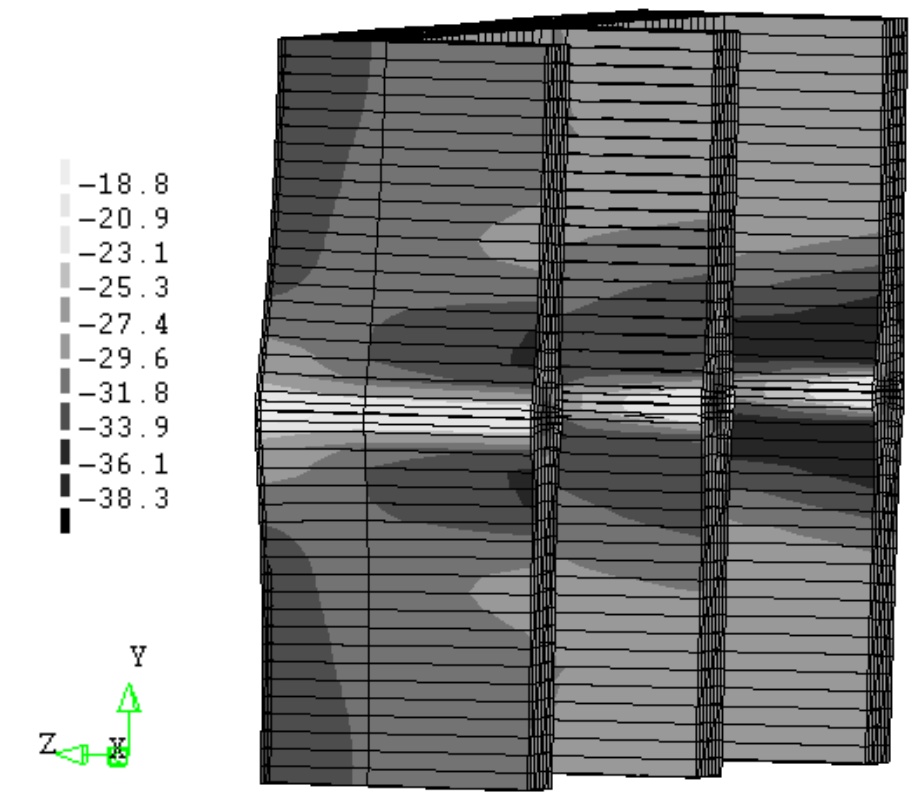

Fig. 14. Minimum principal stresses for the transverse webs, for prism $\mathrm{P} 4$ at failure $\left(\mathrm{N} / \mathrm{mm}^{2}\right)$ 
Table 1. Concrete and mortar mix proportions (in volume)

\begin{tabular}{cccc}
\hline Group & Material & Proportion & $\begin{array}{c}\text { Water/cement } \\
\text { ratio }\end{array}$ \\
\hline \multirow{2}{*}{ P1 } & Concrete & $1: 4.0: 2.4$ & 0.85 \\
& Mortar & $1: 1.3: 5.2$ & 1.26 \\
P2 & Concrete & $1: 4.0: 2.4$ & 0.92 \\
& Mortar & $1: 1.3: 5.3$ & 1.40 \\
P3 & Concrete & $1: 3.2: 2.8$ & 0.75 \\
& Mortar & $1: 0.6: 4.2$ & 0.89 \\
P4 & Concrete & $1: 2.0: 2.7$ & 0.58 \\
& Mortar & $1: 0.3: 3.0$ & 0.78 \\
\hline
\end{tabular}

Concrete proportion (cement: fine aggregate: coarse aggregate)

Mortar proportion (cement: lime: fine aggregate) 
Table 2. Compressive strength of blocks $(b)$, mortar $(m)$ and prisms $(p)$. Value in parenthesis indicates the coefficient of variation (three tests have been performed for each material property)

\begin{tabular}{|c|c|c|c|c|c|}
\hline Prism & $f_{b}^{*}$ & $\begin{array}{c}f_{m} \\
{\left[\mathrm{~N} / \mathrm{mm}^{2}\right]}\end{array}$ & $f_{p}^{*}$ & $\begin{array}{c}f_{p}{ }^{*} / f_{b}{ }^{*} \\
{[-]}\end{array}$ & $\begin{array}{c}f_{m} / f_{b} \\
{[-]}\end{array}$ \\
\hline P1 & $\begin{array}{c}13.7 \\
(2.9 \%)\end{array}$ & 9.4 & $\begin{array}{c}10.2 \\
(1.9 \%)\end{array}$ & 0.74 & 0.69 \\
\hline P2 & $\begin{array}{c}11.2 \\
(4.4 \%)\end{array}$ & 7.7 & $\begin{array}{c}10.0 \\
(3.7 \%)\end{array}$ & 0.89 & 0.69 \\
\hline P3 & $\begin{array}{c}15.0 \\
(2.3 \%)\end{array}$ & 15.5 & $\begin{array}{c}12.0 \\
(4.8 \%)\end{array}$ & 0.80 & 1.03 \\
\hline P4 & $\begin{array}{c}21.8 \\
(2.4 \%)\end{array}$ & 22.2 & $\begin{array}{c}16.9 \\
(3.9 \%)\end{array}$ & 0.78 & 1.02 \\
\hline
\end{tabular}


Table 3. Elastic and inelastic properties of concrete and mortar. Value in parenthesis indicates the coefficient of variation (three tests have been performed for each material property)

\begin{tabular}{|c|c|c|c|c|c|c|c|}
\hline \multicolumn{2}{|c|}{ Prism/Material } & $f_{c}$ & $\begin{array}{c}f_{t} \\
{\left[\mathrm{~N} / \mathrm{mm}^{2}\right]}\end{array}$ & $E$ & $\begin{array}{l}v \\
{[-]}\end{array}$ & \multicolumn{2}{|c|}{$\begin{array}{l}G_{f_{c}} \quad G_{f} \\
{\left[\mathrm{~N} . \mathrm{mm} / \mathrm{mm}^{2}\right]}\end{array}$} \\
\hline \multirow{2}{*}{ P1 } & Mortar & $\begin{array}{c}9.4 \\
(10.5 \%)\end{array}$ & $\begin{array}{c}1.1 \\
(8.3 \%)\end{array}$ & $\begin{array}{c}9745 \\
(5.0 \%)\end{array}$ & $\begin{array}{c}0.127 \\
(3.1 \%)\end{array}$ & $\begin{array}{c}8.3 \\
(5.3 \%)\end{array}$ & $\begin{array}{c}0.0228 \\
(14.4 \%)\end{array}$ \\
\hline & Con & $\begin{array}{c}22.8 \\
(3.5 \%)\end{array}$ & $\begin{array}{c}2.2 \\
(10.1 \%)\end{array}$ & $\begin{array}{l}20595 \\
(8.2 \%)\end{array}$ & $\begin{array}{c}0.203 \\
(2.7 \%)\end{array}$ & $\begin{array}{l}25.92 \\
(2.9 \%)\end{array}$ & $\begin{array}{c}0.127 \\
(26.9 \%)\end{array}$ \\
\hline \multirow{2}{*}{ P2 } & Mor & $\begin{array}{c}7.7 \\
(14.1 \%)\end{array}$ & $\begin{array}{c}0.9 \\
(13.8 \%)\end{array}$ & $\begin{array}{c}8121 \\
(12.3 \%)\end{array}$ & $\begin{array}{c}0.134 \\
(2.4 \%)\end{array}$ & $\begin{array}{c}10.2 \\
(8.7 \%)\end{array}$ & $\begin{array}{c}0.0217 \\
(15.5 \%)\end{array}$ \\
\hline & Cor & $\begin{array}{c}18.6 \\
(4.4 \%)\end{array}$ & $\begin{array}{c}1.7 \\
(12.0 \%)\end{array}$ & $\begin{array}{l}17449 \\
(7.5 \%)\end{array}$ & $\begin{array}{c}0.195 \\
(6.3 \%)\end{array}$ & $\begin{array}{c}26.1 \\
(6.4 \%)\end{array}$ & $\begin{array}{l}0.1063 \\
(17 \%)\end{array}$ \\
\hline \multirow{2}{*}{ P3 } & Mortar & $\begin{array}{c}15.5 \\
(2.3 \%)\end{array}$ & $\begin{array}{c}1.8 \\
(11.7 \%)\end{array}$ & $\begin{array}{l}13195 \\
(4.8 \%)\end{array}$ & $\begin{array}{c}0.151 \\
(4.0 \%)\end{array}$ & $\begin{array}{c}15.48 \\
(9.9 \%)\end{array}$ & $\begin{array}{l}0.0386 \\
(0.3 \%)\end{array}$ \\
\hline & Con & $\begin{array}{c}24.9 \\
(4.0 \%)\end{array}$ & $\begin{array}{c}2.4 \\
(9.3 \%)\end{array}$ & $\begin{array}{l}22175 \\
(5.6 \%)\end{array}$ & $\begin{array}{l}0.204 \\
(2.9 \%)\end{array}$ & $\begin{array}{l}20.38 \\
(3.2 \%)\end{array}$ & $\begin{array}{c}0.1375 \\
(10.0 \%)\end{array}$ \\
\hline \multirow{2}{*}{$\mathrm{P} 4$} & Mortar & $\begin{array}{c}22.2 \\
(7.0 \%)\end{array}$ & $\begin{array}{c}2.6 \\
(4.8 \%)\end{array}$ & $\begin{array}{l}16672 \\
(7.5 \%)\end{array}$ & $\begin{array}{c}0.153 \\
(2.9 \%)\end{array}$ & $\begin{array}{c}17.5 \\
(4.2 \%)\end{array}$ & $\begin{array}{c}0.0653 \\
(11.4 \%)\end{array}$ \\
\hline & Concrete & $\begin{array}{c}36.2 \\
(5.7 \%) \\
\end{array}$ & $\begin{array}{c}3.1 \\
(10.8 \%) \\
\end{array}$ & $\begin{array}{l}27104 \\
(2.1 \%) \\
\end{array}$ & $\begin{array}{c}0.207 \\
(3.2 \%) \\
\end{array}$ & $\begin{array}{c}27.01 \\
(7.9 \%) \\
\end{array}$ & $\begin{array}{r}0.1548 \\
(14.6 \%) \\
\end{array}$ \\
\hline
\end{tabular}


Table 4. Comparison between the numerical and experimental ultimate stress, for the four mortar-block sets. Here, PS indicates plane stress, PE indicates plane strain and 3D indicates threedimensional model.

\begin{tabular}{|c|c|c|c|c|c|c|c|}
\hline \multirow{4}{*}{ Prism } & \multirow{4}{*}{$\begin{array}{l}f^{e x p} \\
{[\mathrm{kN}]}\end{array}$} & \multicolumn{2}{|c|}{ PS } & \multicolumn{2}{|c|}{ PE } & \multicolumn{2}{|c|}{$3 D$} \\
\hline & & $f^{n u m}$ & $f^{\text {num }}$ & $f^{\text {num }}$ & $f^{\text {num }}$ & $f^{\text {num }}$ & $f^{\text {num }}$ \\
\hline & & & $f^{\exp }$ & & $f^{\exp }$ & & \\
\hline & & [kN] & {$[-]$} & {$[\mathrm{kN}]$} & {$[-]$} & [kN] & {$[-]$} \\
\hline $\mathrm{P} 1$ & 10.2 & 6.1 & 0.60 & 14.9 & 1.46 & 9.2 & 0.90 \\
\hline P2 & 10.0 & 4.9 & 0.49 & 12.2 & 1.22 & 8.0 & 0.80 \\
\hline P3 & 12.0 & 10.0 & 0.83 & 16.8 & 1.40 & 11.1 & 0.93 \\
\hline P4 & 16.9 & 14.2 & 0.84 & 24.0 & 1.42 & 17.1 & 1.01 \\
\hline
\end{tabular}


Table 5. Comparison of theoretical and experimental peak strain values in distinct analyses. $\mu$ indicates microns, i.e. that the values should be multiplied by $10^{-6}$.

\begin{tabular}{cccccccc}
\hline & \multirow{2}{*}{$\varepsilon_{u}^{\text {exp }}$} & \multicolumn{2}{c}{ PS } & \multicolumn{2}{c}{ PE } & \multicolumn{2}{c}{ 3D } \\
Prism & & $\varepsilon_{u}^{\text {num }}$ & $\frac{\varepsilon^{\text {num }}}{\varepsilon^{\text {exp }}}$ & $\varepsilon_{u}^{\text {num }}$ & $\frac{\varepsilon^{\text {num }}}{\varepsilon^{\text {exp }}}$ & $\varepsilon_{u}^{\text {num }}$ & $\frac{\varepsilon^{\text {num }}}{\varepsilon^{\text {exp }}}$ \\
& {$[\mu]$} & {$[\mu]$} & {$[-]$} & {$[\mu]$} & {$[-]$} & {$[\mu]$} & {$[-]$} \\
\hline P1 & 2244 & 802 & 0.36 & 2277 & 1.01 & 1488 & 0.66 \\
P2 & 3207 & 711 & 0.22 & 2231 & 0.70 & 1629 & 0.51 \\
P3 & 2451 & 1260 & 0.51 & 2248 & 0.92 & 1503 & 0.61 \\
P4 & 1841 & 1535 & 0.83 & 2591 & 1.41 & 1850 & 1.00 \\
\hline
\end{tabular}

